\title{
Does stabilizing input pressure orthosis vest, lycra-based compression orthosis, improve trunk posture and prevent hip lateralization in children with cerebral palsy?
}

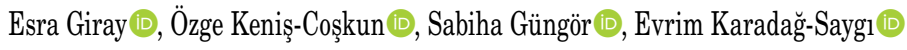 \\ Department of Physical Medicine and Rehabilitation, Marmara University School of Medicine, İstanbul, Turkey
}

Received: January 17, 2017 Accepted: July 21, 2017 Published online: December 15, 2017

\begin{abstract}
Objectives: This study aims to investigate whether the use of a lycra-based compression orthosis known as stabilizing input pressure orthosis (SPIO) vest improves trunk posture and hip lateralization in children with cerebral palsy (CP) and to compare the effects of two- and six-hours daily wear of the orthosis.

Patients and methods: Between December 2013 and July 2015, a total of 24 children with CP (5 boys, 19 girls; mean age 61.1 months; range 35 to 105 months) with impaired trunk control were included in this single-blind, randomized-controlled study. All were randomized to either of the three groups as the control group (received only conventional exercise therapy), the SPIO 2-hour group (worn orthosis two hours during therapy), and the SPIO 6-hour group (worn orthosis four hours in addition to two hours of wear during therapy). The Sitting Assessment Scale (SAS), Cobb angle, kyphotic angle, and Migration Index were used to evaluate the trunk posture and hip lateralization before treatment and at six months after treatment.

Results: The SAS scores improved compared to baseline in all groups. The Cobb angle and kyphotic angle showed a significant decrease at six months after treatment only in the SPIO groups, while intra-group analysis of the Migration Index did not show a statistically significant difference. Changes in the radiographic assessments were similar among the groups, except for the kyphotic angles. The kyphotic angle showed less change in the control group. Comparison of the SPIO groups showed no significant differences in terms of the variables assessed. Conclusion: The SPIO vest improves the kyphotic posture, but not scoliosis and hip lateralization in children with CP with impaired trunk control when used in combination with the conventional therapy. Using the SPIO vest for two and six hours also yields similar outcomes.
\end{abstract}

Keywords: Cerebral palsy; lycra garments; orthosis; sitting; suit therapy; trunk posture.

Posture can be defined as the position of the body segments (i.e., head, trunk, pelvis, and limbs) in relation to one another and their orientation in space. ${ }^{[1]}$ Postural control denotes the control of the body's position in space to obtain stability and orientation. ${ }^{[1]}$ The trunk, being in the center of the body, plays a crucial role in the postural control. ${ }^{[2,3]}$ Integration of sensory input from the visual, vestibular and somatosensory systems, and control of motor system are essential to obtain postural stability and control. ${ }^{[1]}$ Children with cerebral palsy (CP) exhibit impaired trunk control and posture due to inappropriate muscle strength and lack of sensory integration. ${ }^{[4]}$ Receiving sensory cues during rehabilitation may improve postural control. ${ }^{[5,6]}$ In turn, postural management may alleviate hip problems in children with $\mathrm{CP}^{\left[{ }^{[7]}\right.}$

The stabilizing input pressure orthosis (SPIO) vest is a lycra-based compression orthosis which aims to improve proximal stability (Figure 1). ${ }^{[8,9]}$ It provides extra-proprioceptive information which enhances the body awareness, and the correction of the proprioceptive input results in a more proper alignment. ${ }^{[8,9]}$ The proponents of the suit therapy methods have claimed that, once the body and body segments are in an proper alignment, intensive therapy with the suit on yields reeducation of the brain to 
recognize and form the correct movement of the muscles. ${ }^{[10,11]}$

The SPIO vest is composed of a front part which is comprised of double-or triple-layer of lycra fabric attached to Velcro ${ }^{\circ}$-sensitive neoprene back panel. Thus, it provides adjustable compression around the shoulder, trunk, pelvis, and hips. It is proposed that it provides stabilization of the trunk, shoulder and pelvis girdle. ${ }^{[8,9]}$ It has been also shown that the use of dynamic lycra-based orthosis is helpful to inhibit progression of the curve in a neuromuscular scoliosis case. $^{[12]}$ Although its effect on hip lateralization has not been well-established, yet, less hip adduction with a symmetric sitting position has been observed on a quadriplegic cerebral palsy case. ${ }^{[13]}$

In recent years, many studies have reported an increased use of lycra-based compression garments; $;^{[6,8,9,12,13]}$ however, there is a limited number of studies on the effectiveness of these garments on the trunk posture and hip lateralization. In the present study, we aimed to investigate the effectiveness of the SPIO vest on trunk posture and hip lateralization when used in combination with conventional exercise therapy in children with $\mathrm{CP}$. The secondary aim was to compare the effects of two- and six-hours daily wearing of the SPIO vest.

\section{PATIENTS AND METHODS}

Between December 2013 and July 2015, a total of 24 children with CP (5 boys, 19 girls; mean age 61.1 months; range 35 to 105 months) with impaired trunk control were included in this single-blind, randomizedcontrolled study. All children were randomized to either of the three groups: the control group (received only conventional exercise therapy), the SPIO 2-hour group (worn orthosis two hours during therapy), and the SPIO 6-hour group (worn orthosis four hours in addition to two hours of wear during therapy) using opaque, sealed envelopes (NEKS) to which the investigators were blinded. The envelopes were given to the physiotherapist. Before treatment, all parents chose an envelope including an informative message about the group to which the child would be allocated, and the therapist started interventions according to the group allocation.

Children with CP who fulfilled the following inclusion criteria were included in the study: (i) impaired trunk control, (ii) mild-to-moderate, diplegic or tetraplegic spastic CP, (iii) aged between 35 and 105 months, (iv) the Gross Motor Function Classification System (GMFCS) level III-IV, (v) being able to understand and execute given instructions for the evaluations, and ( $v i$ ) parental acceptance of using the lycra-based compression garments. Exclusion criteria were as follows: (i) contraindications for the use of compression garments such as having serious respiratory dysfunction, refractory cyanosis or circulatory disorder; reflux more than three times a week, (ii) having lycra-based compression orthosis treatment program previously, (iii) having botulinum toxin injection within the past three months or orthopedic surgery within one year, (iv) severe scoliosis (Cobb angle $[\mathrm{CA}]>40^{\circ}$ ), (v) uncontrolled epilepsy, (vi) having intrathecal baclofen pump, and (vii) having selective dorsal rhizotomy.

The sample size was calculated on the basis of the previously reported the mean change of the Sitting Assessment Scale (SAS) total score in the study conducted by Simsek et al. ${ }^{[4]}$ Power analysis using a power of $80 \%$ and a significance of $\mathrm{p}=0.05$ showed that at least eight children for each group had to be
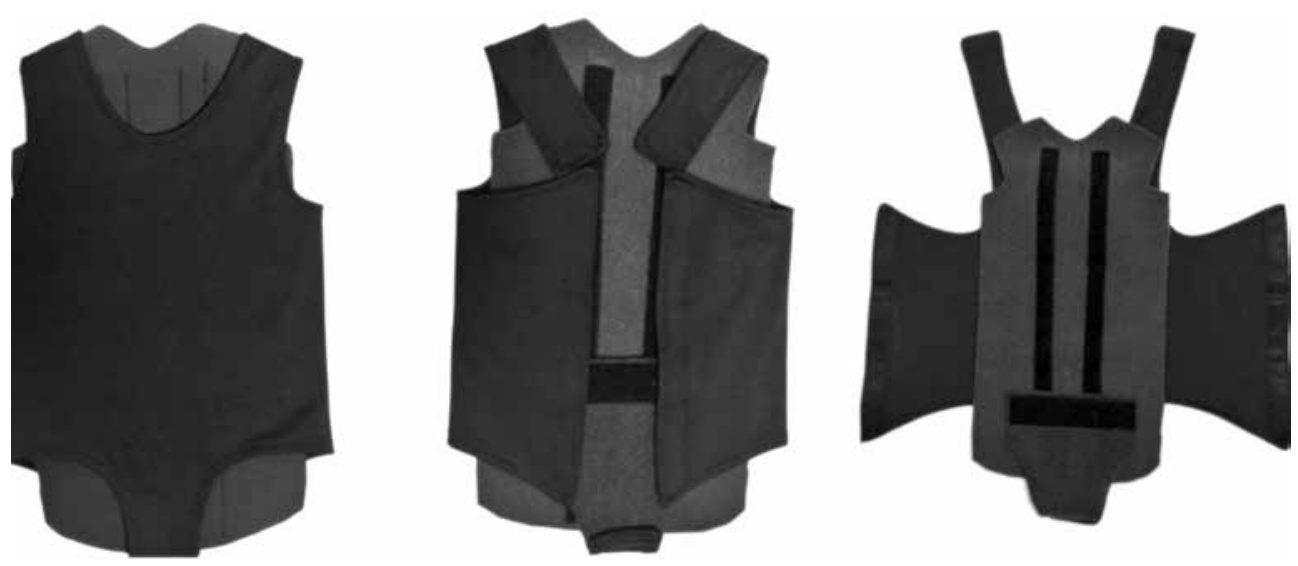

Figure 1. Stabilizing input pressure orthosis vest. 
recruited to detect a minimum clinically significant difference of 1 unit of the SAS score between the groups, when the mean expected value in the first group was 16.47 with a standard deviation of 1.96 and the mean expected value in the second group was 13.20 with a standard deviation of 3.32 .

Allowing for a conservative drop-out or loss to follow-up rate of about $20 \%, 26$ children with CP who met the inclusion criteria were recruited in the study. An oral and written informed consent was obtained from each parent. The study protocol was approved by the Ethics Committee of Marmara University School of Medicine. The study was conducted in accordance with the principles of the Declaration of Helsinki.

\section{Interventions}

All children were hospitalized for two weeks. All groups received conventional exercise therapy including the range of motion, strengthening, trunk control, and strengthening exercises in addition to exercises to improve fine and gross motor skills throughout their hospitalization, two hours per day, seven days per week. The control group received conventional exercise therapy alone. The SPIO 2-hour group received conventional exercise therapy with the garment on during two hours, while the SPIO 6-hour group wore the SPIO for four hours more in addition to two hours of wear during therapy.

During the follow-up after discharge, both SPIO groups continued wearing the orthoses at home. All children continued their regular therapies for one hour a day, two days a week. During follow-up, the wear time of garments was checked by phone calls on a weekly basis. No other changes in the physiotherapy or orthotic management or no addition of a new treatment method were allowed during follow-up.

\section{Outcome measures}

The SAS was used to evaluate the posture and balance during sitting. The Cobb (CA) and kyphotic angles (KA) were determined to find out the effect of the orthosis on trunk posture, while the Migration Index (MI) was calculated to examine the effect of orthosis on hip lateralization. To assess inter-rater reliability, radiographic measurements were carried out by two different investigators. All assessments were conducted before treatment (BT) and at six months after treatment (6MPT). The children were not allowed wearing the garment during the assessments.

The SAS was developed for the observational assessment of posture and balance during sitting after seating interventions. The scale consists of five items including head control, trunk control, foot control, arm function, and hand function which are assessed as follows: $1=$ none; 2 = poor; $3=$ fair; $4=$ good). The minimum and maximum scores range from 5 to 20 . The SAS has a high intra- (intra-class correlation coefficient [ICC] 0.87-1.0) and inter-rater reliability (ICC 0.87-1.0)..$^{[14,15]}$

In addition, the $\mathrm{CA}$ and $\mathrm{KA}$ was measured using specific digital X-ray analysis software (Surgimap version 2.2.2) (Nemaris Inc., NY, USA). The MI was calculated using the Picture Archiving Communication Systems (PACS) system (INFINITT Healthcare,

Table 1. Demographic features of the groups

\begin{tabular}{|c|c|c|c|c|c|c|c|c|c|c|c|c|c|}
\hline & & & PIO 2-ho & & & & PIO 6-hou & & & & Control & & \\
\hline & $\mathrm{n}$ & $\%$ & Median & Min-Max & $\mathrm{n}$ & $\%$ & Median & Min-Max & $\mathrm{n}$ & $\%$ & Median & Min-Max & $p$ \\
\hline Age (month) & & & 68 & $38-88$ & & & 55.5 & $41-105$ & & & 51.5 & $35-92$ & $0.67^{\star} \neq$ \\
\hline Sex & & & & & & & & & & & & & $0.78 \dagger \ddagger$ \\
\hline Female & 2 & 8.3 & & & 1 & 4.2 & & & 2 & 8.3 & & & \\
\hline Male & 6 & 25 & & & 7 & 29.2 & & & 6 & 25 & & & \\
\hline Cerebral palsy type & & & & & & & & & & & & & $0.58 \dagger 末$ \\
\hline Diplegic & 1 & 4.2 & & & 0 & 0 & & & 1 & 4.2 & & & \\
\hline Tetraplegic & 7 & 29.2 & & & 8 & 33.3 & & & 7 & 29.2 & & & \\
\hline GMFCS & & & & & & & & & & & & & $0.78 \dagger \ddagger$ \\
\hline Level 3 & 2 & 8.3 & & & 2 & 8.3 & & & 1 & 4.2 & & & \\
\hline Level 4 & 6 & 25 & & & 6 & 25 & & & 7 & 29.2 & & & \\
\hline SAS & & & 12 & $7-16$ & & & 13 & $10-16$ & & & 14 & $9-15$ & $0.46^{*} \neq$ \\
\hline MI right & & & 28.1 & $9-35.8$ & & & 24.8 & $17.1-47.4$ & & & 25 & $15.7-45.9$ & $0.83^{*} \ddagger$ \\
\hline MI left & & & 17.91 & $7.4-61.7$ & & & 22.07 & $15.6-51.2$ & & & 21.99 & $13.3-57.1$ & $0.66^{*} \neq$ \\
\hline $\mathrm{CA}$ & & & 8 & $6-10$ & & & 7 & $5-15$ & & & 7 & $3-13$ & $0.21^{\star} \ddagger$ \\
\hline KA & & & 42 & $33-48$ & & & 41 & $33-56$ & & & 39 & $24-53$ & $0.85^{\star} \neq$ \\
\hline
\end{tabular}

SPIO: Stabilizing input pressure orthosis; Min: Minimum; Max: Maximum; ${ }^{\star}$ Kruskal Wallis, $\dagger$ Chi square test, $\ddagger$ p $>0.005$; GMFCS: Gross Motor Function Classification System; SAS: Sitting Assessment Scale; MI: Migration Index; CA: Cobb angle; KA: Kyphotic angle. 
Seoul, South Korea). Two researchers carried out the measurements independently.

When calculating the CA, the technique described by Oguz et al. ${ }^{[16]}$ was used to decide which vertebrae were forming the upper and lower limits of the scoliotic curve. Those vertebrae are called end vertebrae. Intervertebral disc (IVD) spaces are narrowed on the concave side of curve. The vertebral levels which IVD spaces start to get wider are measured as the upper and lower end vertebral levels. The angle between the lines which are drawn parallel to the upper endplate of the superior end vertebra and lower endplate of inferior end vertebra forms the CA.

To calculate the KA, the angle between the lines drawn along the upper endplate of $\mathrm{T}_{4}$ vertebra and lower endplate of $\mathrm{T}_{12}$ vertebra is calculated. ${ }^{[16]}$
Furthermore, the MI shows lateralization of femur with the percentage of the femoral head found lateral to the acetabular margin. To measure MI, one must draw a line through the triradiate cartilages (Hilgenreiner's line) and a vertical line (Perkin's line) at the outer margin of the acetabulum and perpendicular to the Hilgenreiner's line. The proportion of the femoral head out of the Perkin's line to entire measure of the femoral head gives the MI. ${ }^{[17]}$

\section{Statistical analysis}

The sample size estimation was performed using the MedCalc for Windows version 12.2.1 (MedCalc Software, Mariakerke, Belgium). Statistical analysis was performed using the IBM SPSS for Windows version 20.0 software (IBM Corp., Armonk, NY, USA).

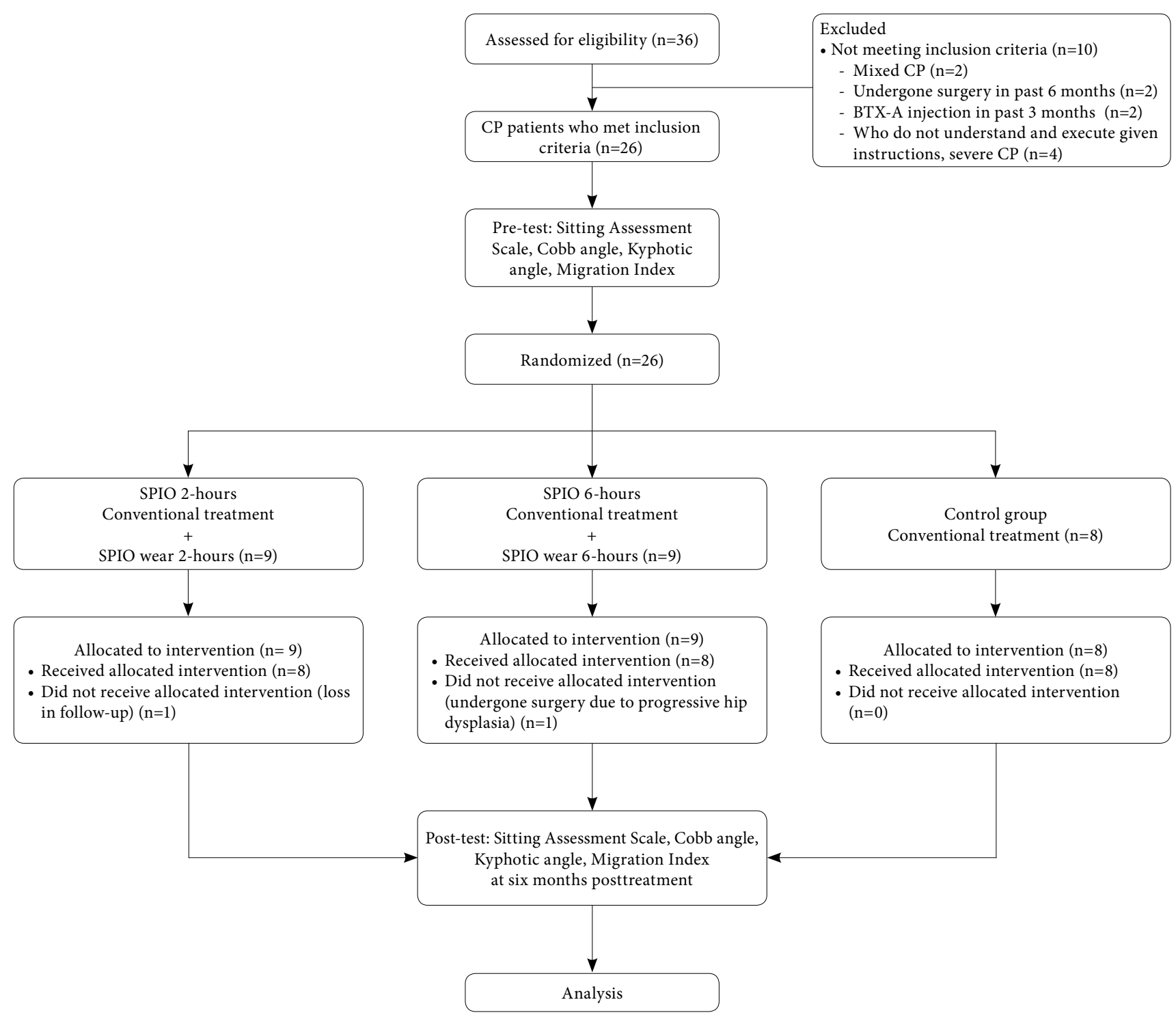

Figure 2. Consort diagram of study. CP: Cerebral palsy; BTX-A: Botulinum toxin; SPIO: Stabilizing input pressure orthosis. 
Table 2. Interclass correlation coefficients for radiologic measurements

\begin{tabular}{lccc}
\hline & $\mathrm{r}$ & $\mathrm{ICC}$ & $\% 95 \mathrm{CI}$ \\
\hline $\mathrm{MI}_{\mathrm{R}}$ BT & $0.92^{*}$ & 0.87 & $0.71-0.94 \dagger$ \\
$\mathrm{MI}_{\mathrm{L}}$ BT & $0.96^{* *}$ & 0.99 & $0.96-0.99 \dagger$ \\
$\mathrm{MI}_{\mathrm{R}}$ 6MPT & $0.86^{*}$ & 0.86 & $0.83-0.97 \dagger$ \\
$\mathrm{MI}_{\mathrm{L}}$ 6MPT & $0.82^{* *}$ & 0.93 & $0.79-0.97 \dagger$ \\
$\mathrm{KA} \mathrm{BT}$ & $0.97^{* *}$ & 0.97 & $0.94-0.99 \dagger$ \\
$\mathrm{KA} \mathrm{6MPT}$ & $0.88^{*}$ & 0.83 & $0.61-0.93 \dagger$ \\
$\mathrm{CA} \mathrm{BT}$ & $0.95^{*}$ & 0.89 & $0.76-0.95 \dagger$ \\
CA 6MPT & $0.89^{*}$ & 0.85 & $0.66-0.94 \dagger$ \\
\hline
\end{tabular}

CI: Confidence interval; ${ }^{*} \mathrm{p}<0.001$ by Pearson; ${ }^{* *} \mathrm{p}<0.001$ by Spearman correlation tests; $\dagger$ ICC $=0.75$ to 1.00 excellent reliability; $\mathrm{MI}_{\mathrm{R}}$ : Migration Index on the right side; BT: Before treatment; $\mathrm{MI}_{\mathrm{L}}$ : Migration Index on the left side; MPT: Month posttreatment; KA: Kyphotic angle; CA: Cobb angle.

The histogram and normality plots and Shapiro-Wilk normality test were used for data distribution analysis. Descriptive statistics were calculated using tables of frequencies for the ordinal variables and expressed in median (min-max) for the non-normally disturbed variables. The chi-square $\left(\chi^{2}\right)$ was used to compare categorical variables. Within the group differences were analyzed using the Wilcoxon signed-rank test. Differences between the groups were tested by the Kruskal-Wallis test. The Mann-Whitney U test was used to analyze the significance of pairwise differences using the Bonferroni correction (post-hoc test) to adjust for multiple comparisons. Using the Bonferroni correction, a $p$ value of less than $0.017(0.05 / 3)$ was considered statistically significant. Correlations between the radiographic measurements obtained from two different researchers were calculated using the Pearson correlation test for Migration Index on the left side $\left(\mathrm{MI}_{\mathrm{L}}\right) \mathrm{BT}, \mathrm{MI}_{\mathrm{L}} 6 \mathrm{MPT}$, and $\mathrm{KA} \mathrm{BT}$ and Spearman correlation analysis for $\mathrm{MI}_{\mathrm{L}} \mathrm{BT}, \mathrm{MI}_{\mathrm{L}}$ 6MPT, and KA BT values. The inter-rater reliability of radiographic measurements was estimated using the ICC. The values of the ICC ranged from 0 to 1 with a higher value indicating better reliability. The ICC less than 0.40 was considered as poor; 0.40 to 0.59 as fair; 0.60 to 0.74 as good, and 0.75 to 1.00 as excellent. ${ }^{[18]}$ A post-hoc power analysis was conducted using the G-Power version 3.1.9.2 (Heinrich-Heine-Universität, Düsseldorf, Germany) for the statistically significant test results. A $p$ value of $<0.05$ was considered statistically significant.

\section{RESULTS}

There were no significant differences between the demographic and clinical characteristics of the groups (Table 1). Figure 2 shows Consolidated Standards of Reporting Trials (CONSORT) diagram of the study. Among 36 children evaluated for recruitment, 26 of them met the inclusion criteria. There were two drop-outs throughout the follow-up period. Finally, data from 24 children were analyzed. Correlations between the measurements performed

Table 3. Sitting Assessment Scale scores and radiographic measurements of groups before and after six months post-treatment

\begin{tabular}{|c|c|c|c|c|c|}
\hline \multirow[t]{2}{*}{ Assessments } & \multicolumn{2}{|c|}{ Before treatment } & \multicolumn{2}{|c|}{ At six months post-treatment } & \multirow[b]{2}{*}{$p$} \\
\hline & Median & Min-Max & Median & Min-Max & \\
\hline \multicolumn{6}{|c|}{ Sitting Assessment Scale score } \\
\hline SPIO 2-hours $(\mathrm{n}=8)$ & 12 & $7-16$ & 18 & $15-20$ & $0.011 \ddagger \S \dagger$ \\
\hline SPIO 6-hours $(\mathrm{n}=8)$ & 13 & $10-16$ & 20 & $17-20$ & $0.011 \ddagger \S \dagger$ \\
\hline Control $(\mathrm{n}=8)$ & 14 & $9-15$ & 16 & $11-18$ & $0.011 \neq \$ \dagger$ \\
\hline \multicolumn{6}{|l|}{ Migration Index right } \\
\hline SPIO 2-hours $(\mathrm{n}=8)$ & 28.1 & $9-35.8$ & 29.41 & $9.9-46.2$ & $0.37 \ddagger$ \\
\hline SPIO 6-hours $(\mathrm{n}=8)$ & 24.8 & $17.1-47.4$ & 26.52 & $15.9-40.3$ & $0.85 \ddagger$ \\
\hline Control $(\mathrm{n}=8)$ & 25 & $15.7-45.9$ & 34.3 & $23-44.2$ & $0.3 \ddagger$ \\
\hline \multicolumn{6}{|l|}{ Migration Index left } \\
\hline SPIO 2-hours $(\mathrm{n}=8)$ & 17.91 & $7.4-61.7$ & 33 & $17.3-68.0$ & $0.08 \ddagger^{*}$ \\
\hline SPIO 6-hours $(\mathrm{n}=8)$ & 22.07 & $15.6-51.2$ & 29.59 & $17.3-48.1$ & $0.22 \ddagger$ \\
\hline Control $(n=8)$ & 21.99 & $13.3-57.1$ & 24.62 & $13.3-64.5$ & $0.46 \ddagger$ \\
\hline \multicolumn{6}{|l|}{ Cobb angle } \\
\hline SPIO 2-hours $(\mathrm{n}=8)$ & 8 & $6-10$ & 6 & $3-8$ & $0.012 \ddagger \S \dagger$ \\
\hline SPIO 6-hours $(\mathrm{n}=8)$ & 7 & $5-15$ & 5.5 & $1-6$ & $0.027 \ddagger \S \dagger$ \\
\hline Control $(\mathrm{n}=8)$ & 7 & $3-13$ & 8 & $2-14$ & $0.93 \ddagger$ \\
\hline \multicolumn{6}{|l|}{ Kyphotic angle } \\
\hline SPIO 2-hours $(\mathrm{n}=8)$ & 42 & $33-48$ & 33 & $27-45$ & $0.03 \ddagger \$ \dagger$ \\
\hline SPIO 6-hours $(\mathrm{n}=8)$ & 41 & $33-56$ & 40 & $15-51$ & $0.04 \ddagger \$ \dagger$ \\
\hline Control $(\mathrm{n}=8)$ & 39 & $24-53$ & 38 & $23-41$ & $0.16 \ddagger$ \\
\hline
\end{tabular}

Min: Minimum; Max: Maximum; $\ddagger$ Wilcoxon Signed Rank test; $₫$ Statistically significant; $\dagger$ Post hoc power $>99 \%$; ${ }^{\star}$ Post hoc power $>80 \%$; SPIO: Stabilizing input pressure orthosis. 


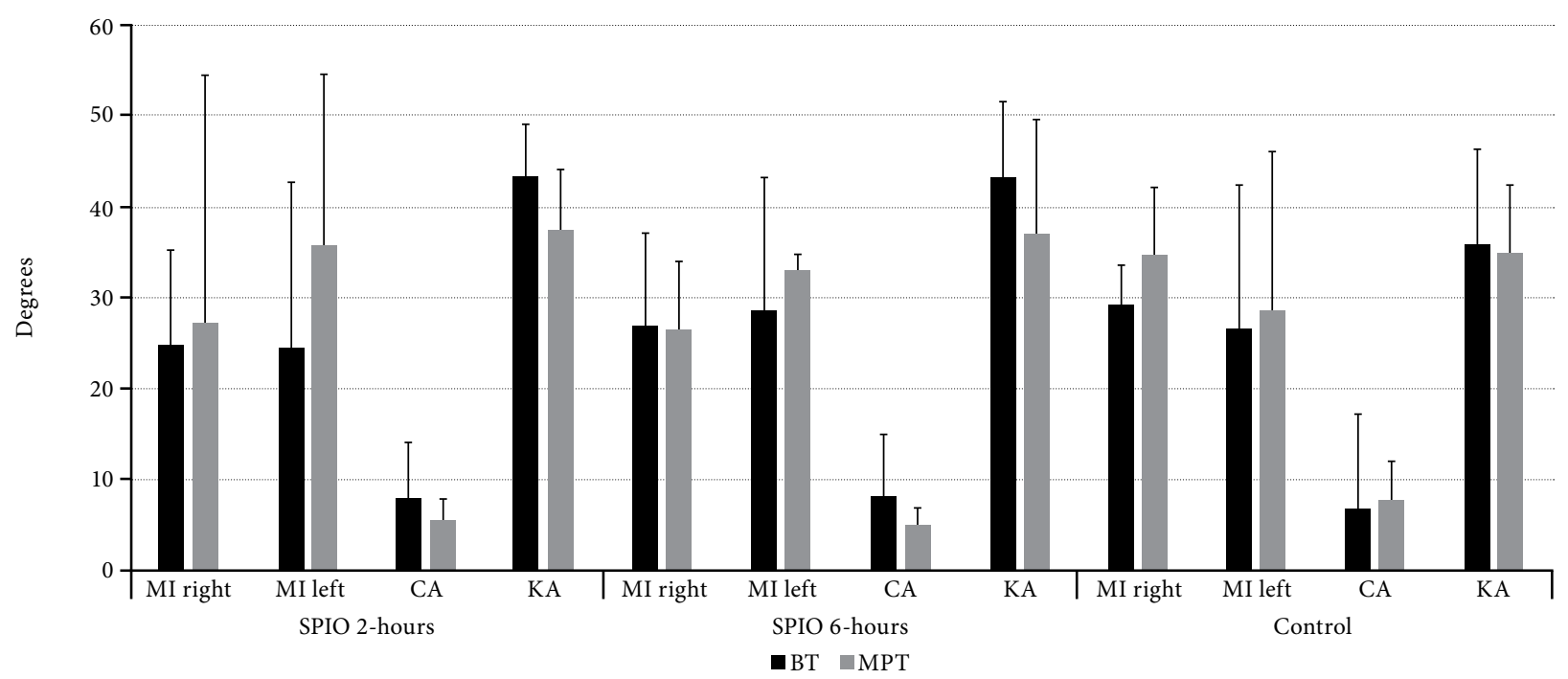

Figure 3. Changes in the groups after the treatment. MI: Migration Index; CA: Cobb angle; KA: Kyphotic angle; BT: Before treatment; MPT: Month posttreatment.

Table 4. Comparison of changes in Sitting Assessment Scale scores and measurements between baseline and six months post-treatment in each group

\begin{tabular}{|c|c|c|c|c|c|c|c|}
\hline & \multicolumn{2}{|c|}{ SPIO 2-hours } & \multicolumn{2}{|c|}{ SPIO 6-hours } & \multicolumn{2}{|c|}{ Control } & \multirow[b]{2}{*}{$p$} \\
\hline & Median & Min-Max & Median & Min-Max & Median & Min-Max & \\
\hline Sitting Assessment Scale scores & 6 & $3-8$ & 5.5 & $4-10$ & 2 & $1-4^{*}$ & $0.001 \neq \$ \dagger$ \\
\hline Migration Index right & 2.34 & $-6.1-33.23$ & -1.4 & $-7.08-7.14$ & 7.13 & $-14.13-34.7$ & $0.42 \ddagger \dagger$ \\
\hline Migration Index left & 9.01 & $-5.66-38.02$ & 5.11 & $-8.42-13.19$ & -0.26 & $-4.79-11.31$ & $0.42 \ddagger \dagger$ \\
\hline Cobb angle & -3 & $-8--1$ & -4.5 & $-18-0$ & 0 & $-21-5$ & $0.07 \ddagger \dagger$ \\
\hline Kyphotic angle & -2 & $-6-0$ & -2 & $-9-0$ & 1 & $-1-3^{* *}$ & $0.018 \ddagger \S \dagger$ \\
\hline
\end{tabular}

Min: Minimum; Max: Maximum; $¥$ Kruskall Wallis test; ${ }^{*} \mathrm{p}=0.63$ (SPIO 2-hours-SPIO 6-hours); $\mathrm{p}=0.001$ (SPIO 6-hours- Control); $\mathrm{p}=0.001$ (SPIO 2-hours- Control) by MannWhitney U test; $₫$ Statistically significant; ${ }^{* *} \mathrm{p}=0.63$ (SPIO 2-hours-SPIO 6-hours); $\mathrm{p}=0.01$ (SPIO 6-hours- Control); $\mathrm{p}=0.013$ (SPIO - Control) by Mann-Whitney U test; $\dagger$ post hoc power $>99 \%$.

by two independent investigators were found to be significantly high. (Table 2).

\section{Intra-group analysis}

There were statistically significant differences in the SAS for all groups at 6MPT, compared to baseline (Table 3). None of the groups showed change in the MI of the right or left hip. While the CA and KA decreased significantly in the SPIO groups, neither KA nor CA was significantly different at $6 \mathrm{MPT}$, compared to baseline, in the control group (Table 3, Figure 3).

\section{Inter-group analysis}

After treatment, all groups showed an increase in the SAS scores; however, the increase in the SAS was significantly less in the control group than the others (Table 4, Figure 3). Regarding the radiological measurements, decrease in the KA in the control group after treatment was significantly lower than the decrease in the KA in the SPIO groups. The changes in the CA and MI after treatment did not significantly differ among groups (Table 4). When the SPIO 2-hour and SPIO 6-hour groups were compared, there were no significant differences in any of the variables assessed. Figure 3 represents the changes in the measurements in the SPIO and control groups after the treatment.

\section{DISCUSSION}

To investigate the effect of the SPIO vest on trunk posture and hip of children with CP who had impaired trunk control, posture and balance during sitting, trunk asymmetry and hip lateralization were evaluated. In the SPIO groups, CA and KA decreased, compared to baseline, while it remain unchanged in the control group. Changes in the CA and MI were similar among the groups, while change in the KA in the control group was lower than the SPIO groups. 
In a neurological scoliosis case, a kind of dynamic lycra-based orthosis applying derotational forces was found to decrease the CA from $33^{\circ}$ to $15^{\circ}$. The CA was held at $20^{\circ}$ for 30 months with 23 hours of wear every day. The possible mechanisms of this effect were explained by the authors with the several advantages of the lycra-based orthoses. First, it improves spinal alignment with increased body awareness. Second, the muscle strength does not reduce in contrast to the rigid orthosis use. Third, it is more cosmetic than rigid braces. As a result, patient compliance is high and makes it easier for the patients to wear the orthosis for longer periods of time. ${ }^{[12]}$ Although the SPIO vest used in this study did not have the property of applying derotational forces, the CA and KA in the SPIO groups decreased after the treatment. Similar to results of the present study, in a randomized-controlled trial conducted by Azab et al., ${ }^{[19]}$ TheraSuit, a kind of orthotic garment, improved trunk posture of spastic diplegic children with CP, when added to the treatment program. Trunk posture was evaluated via threedimensional posture analysis system which is capable of measuring trunk imbalance, pelvic tilt, surface rotation, and lateral deviation. Similar to our results, wearing the TheraSuit resulted in a better upright sitting position and less lateral deviation of trunk.

The MI did not show any change at $6 \mathrm{MPT}$, compared to baseline. Consistent with the results of this study, Park et al. ${ }^{[20]}$ found out that the KA and CA significantly decreased in study group who received electrical stimulation on back muscles to improve trunk control; however, there was no change in the lumbosacral angle after the treatment.

In an another study, contrary to our findings, $\mathrm{Knox}^{[13]}$ reported that full body lycra suit permitted adduction of hips by allowing legs to be more symmetrical while sitting. However, this was a subjective observational result. When it is considered that there is a strong relationship between the sagittal spinal and pelvic parameters, better hip posture can be obtained with an improved spinal alignment. ${ }^{[21]}$ Pelvic obliquity plays a crucial role in the pathogenesis of scoliosis in CP. Pelvic obliquity of the upper origin may be the result of asymmetric contraction of the trunk muscles on different sides, while pelvic obliquity of the lower origin is a result of deteriorated hip posture which, in turn, causes progression of existing scoliosis. ${ }^{[22]}$ The reason why Knox's ${ }^{[13]}$ findings are contrary to our results may be that the full body suit contains parts, which may be effective on both upper and lower origin of pelvic obliquity, while the SPIO vest may be effective for only upper origin. Also, similar to our findings, Willoughby et al. ${ }^{[23]}$ concluded that complementary and alternative treatments did not prevent hip lateralization and, while seeking alternative therapies, children with CP should not miss the chance of early surgery, which is less complex and invasive.

Suit therapies to improve body alignment and functions in children with CP have become remarkably popular in recent years and are widely used in pediatric rehabilitation settings. There is a surge in the literature investigating the effects of suit therapies. ${ }^{[6,8-13,19,24-28]}$ Comparison among the findings of this study and others is difficult due to the heterogeneity of subjects, type of suits used, age of the participants, and the GMFCS level of participants. Also, there is no standardized wear time for the suits. We aimed to choose one type of garment vest only (not including whole body suit, pants etc.), and we aimed to focus on investigating its effects only improving trunk posture and thus hip lateralization to prevent from confusing results.

Depending on the topography and severity of the motor impairment, trunk control and posture are impaired in children with $\mathrm{CP}$ to a various extent. Since trunk control is most impaired in children with diplegic and tetraplegic topographic types and at higher GMFCS levels, children with diplegic and tetraplegic CP with GMFCS levels of III-IV were included in the present study to eliminate the confounding results emerging from heterogeneous types and GMFCS levels. ${ }^{[3]}$ To establish the effectiveness of suit therapies, researches should narrow the focus of investigation and choose which type of garment to use and specify CP type and GMFCS level.

The main limitations of the study are as follows: First, small sample size of the study does not allow us to draw a final conclusion about the effects of suit. Second, outcome measures used to assesses body structure and function only. Effects of suit on activity and participation were unable to be evaluated. Blinded, randomized-controlled design and evaluation of the inter-rater reliability of the radiographic measurements can be viewed as the strengths of this study. In addition, to the best of our knowledge, the present study is the first to evaluate the effects of a lycra-based compression garment orthosis on trunk posture and hip lateralization in children with CP.

In conclusion, the stabilizing input pressure orthosis vest improves kyphotic posture, but not scoliosis and hip lateralization, when used in combination with conventional exercises. Therefore, it can be used to improve sitting posture combined with conventional therapy. Since wearing this orthosis for two and six 
hours are also equally effective, two hours of wear can be recommended to children with low compliance to suit therapies. Finally, further large-scale studies are needed to confirm these findings.

\section{Acknowledgements}

We would like to express our gratitude to the parents and children who participated in this study, and Pinar Ay, Marmara University School of Medicine, Department of Public Health, Istanbul, Turkey for her valuable contributions for sample size estimation.

\section{Declaration of conflicting interests}

The authors declared no conflicts of interest with respect to the authorship and/or publication of this article.

\section{Funding}

The authors received no financial support for the research and/or authorship of this article.

\section{REFERENCES}

1. Brogren E, Hadders-Algra M, Forssberg H. Postural control in sitting children with cerebral palsy. Neurosci Biobehav Rev 1998;22:591-6.

2. Sæther R, Jørgensen L. Intra- and inter-observer reliability of the Trunk Impairment Scale for children with cerebral palsy. Res Dev Disabil 2011;32:727-39.

3. Heyrman L, Desloovere K, Molenaers G, Verheyden G, Klingels K, Monbaliu E, et al. Clinical characteristics of impaired trunk control in children with spastic cerebral palsy. Res Dev Disabil 2013;34:327-34.

4. Şimşek TT, Türkücüoğlu B, Çokal N, Üstünbaş G, Şimşek İE. The effects of Kinesio taping on sitting posture, functional independence and gross motor function in children with cerebral palsy. Disabil Rehabil 2011;33:2058-63.

5. Dusing SC. Postural variability and sensorimotor development in infancy. Dev Med Child Neurol 2016;58:17-21.

6. Bahramizadeh $M$, Rassafiani $M$, Aminian G, Rashedi V, Farmani F, Mirbagheri SS. Effect of Dynamic Elastomeric Fabric Orthoses on Postural Control in Children With Cerebral Palsy. Pediatr Phys Ther 2015;27:349-54.

7. Picciolini O, Albisetti W, Cozzaglio M, Spreafico F, Mosca F, Gasparroni V. "Postural Management" to prevent hip dislocation in children with cerebral palsy. Hip Int 2009;19:56-62.

8. Hylton N, Allen C. The development and use of SPIO Lycra compression bracing in children with neuromotor deficits. Pediatr Rehabil 1997;1:109-16.

9. Blair E, Ballantyne J, Horsman S, Chauvel P. A study of a dynamic proximal stability splint in the management of children with cerebral palsy. Dev Med Child Neurol 1995;37:544-54

10. Lee BH. Clinical usefulness of Adeli suit therapy for improving gait function in children with spastic cerebral palsy: a case study. J Phys Ther Sci 2016;28:1949-52.

11. Bailes AF, Greve K, Schmitt LC. Changes in two children with cerebral palsy after intensive suit therapy: a case report. Pediatr Phys Ther 2010;22:76-85.
12. Matthews M, Crawford R. The use of dynamic Lycra orthosis in the treatment of scoliosis: a case study. Prosthet Orthot Int 2006;30:174-81.

13. Knox V. The use of Lycra garments in children with cerebral palsy: A report of a descriptive clinical trial. BJOT 2003;66:71-7.

14. Myhr U, von Wendt L. Improvement of functional sitting position for children with cerebral palsy. Dev Med Child Neurol 1991;33:246-56.

15. Myhr U, von Wendt L, Norrlin S, Radell U. Five-year followup of functional sitting position in children with cerebral palsy. Dev Med Child Neurol 1995;37:587-96.

16. Oğuz E, Ekinci Ş, Erşen Ö. Ergen idiopatik skolyozda radyolojik değerlendirme ve sinıflama sistemlerinin incelenmesi. TOTBİD Dergisi 2013;12:73-82.

17. Parrott J, Boyd RN, Dobson F, Lancaster A, Love S, Oates J, et al. Hip displacement in spastic cerebral palsy: repeatability of radiologic measurement. J Pediatr Orthop 2002;22:660-7.

18. Gstoettner M, Sekyra K, Walochnik N, Winter P, Wachter $\mathrm{R}$, Bach CM. Inter- and intraobserver reliability assessment of the Cobb angle: manual versus digital measurement tools. Eur Spine J 2007;16:1587-92.

19. Azab ASR, Hamed SA. Effect of suit therapy on back geometry in spastic diplegic cerebral palsied children. Journal of American Science 2014;10:245-51.

20. Park ES, Park CI, Lee HJ, Cho YS. The effect of electrical stimulation on the trunk control in young children with spastic diplegic cerebral palsy. J Korean Med Sci 2001;16:347-50.

21. Suh DH, Hong JY, Suh SW, Park JW, Lee SH. Analysis of hip dysplasia and spinopelvic alignment in cerebral palsy. Spine J 2014;14:2716-23.

22. Vialle R, Thévenin-Lemoine C, Mary P. Neuromuscular scoliosis. Orthopaedics \& Traumatology: Surgery \& Research 2013;99:124-39.

23. Willoughby K, Jachno K, Ang SG, Thomason P, Graham HK. The impact of complementary and alternative medicine on hip development in children with cerebral palsy. Dev Med Child Neurol 2013;55:472-9.

24. Angilley H. Lycra Garments, a single case study. APCP Journal 2006:14-18.

25. Cheng C, Iris C. Use of a lycra-based garment in facilitating postural stability in children with cerebral palsy. Hong Kong Society of Child Neurology \& Developmental Paediatrics 2003. Available from: http://jcmfclc.sahk1963. org.hk/main_C4c.htm

26. Bailes AF, Greve K, Burch CK, Reder R, Lin L, Huth MM. The effect of suit wear during an intensive therapy program in children with cerebral palsy. Pediatr Phys Ther 2011;23:136-42.

27. Flanagan A, Krzak J, Peer M, Johnson P, Urban M. Evaluation of short-term intensive orthotic garment use in children who have cerebral palsy. Pediatr Phys Ther 2009;21:201-4.

28. Coghill JE, Simkiss DE. Question 1. Do Lycra garments improve function and movement in children with cerebral palsy? Arch Dis Child 2010;95:393-5. 